\title{
Cost-effectiveness of a physician-nurse supplementary triage assessment team at an academic tertiary care emergency department
}

\author{
Ivy Cheng, MD, MSc* ${ }^{\dagger}$; Maaret Castren, MD, PhD*; Alex Kiss, $\mathrm{PhD}^{\ddagger}$; Merrick Zwarenstein, $\mathrm{MD}, \mathrm{PhD}^{\Uparrow}$; \\ Mats Brommels, MD, $\mathrm{PhD}^{\|}$; Nicole Mittmann, $\mathrm{MSc} \mathrm{PhD}^{\S}$
}

\begin{abstract}
Objective: The purpose of this study was to evaluate the cost-effectiveness of physician-nurse supplementary triage assistance team (MDRNSTAT) from a hospital and patient perspective.

Methods: This was a cost-effectiveness evaluation of a cluster randomized control trial comparing the MDRNSTAT with nurseonly triage in the emergency department (ED) between the hours of 0800 and 1500. Cost was MDRNSTAT salary. Revenue was from Ontario's Pay-for-Results and patient volume-case mix payment programs. The incremental cost-effectiveness ratio was based on MDRNSTAT cost and three consequence assessments: 1) per additional patient-seen; 2) per physician initial assessment (PIA) hour saved; and 3) per ED length of stay (EDLOS) hour saved. Patient opportunity cost was determined. Patient satisfaction was quantified by a cost-benefit ratio. A sensitivity analysis extrapolating MDRNSTAT to different working hours, salary, and willingness-to-pay data was performed. Results: The added cost of the MDRNSTAT was $\$ 3,597.27[\$ 1,729.47$ to $\infty]$ per additional patient-seen, $\$ 75.37$ [ $\$ 67.99$ to $\$ 105.30$ ] per PIA hour saved, and $\$ 112.99$ [\$74.68 to $\$ 251.43$ ] per EDLOS hour saved. From the hospital perspective, the cost-benefit ratio was 38.6 [19.0 to $\infty$ ] and net present value of $-\$ 447,996$ [ $\$ 435,646$ to $-\$ 459,900]$. For patients, the cost-benefit ratio for satisfaction was 2.8 [2.3 to 4.6]. If MDRNSTAT performance were consistently implemented from noon to midnight, it would be more cost-effective.

Conclusions: The MDRNSTAT is not a cost-effective daytime strategy but appears to be more feasible during time periods with higher patient volume, such as late morning to evening.
\end{abstract}

\section{RÉSUMÉ}

Objectif: L'étude avait pour but d'évaluer le rapport coûtefficacité d'une équipe supplémentaire d'aide au triage, formée d'infirmières et d'un médecin (acronyme anglais: MDRNSTAT), du point de vue de I'hôpital et de celui des patients.

Méthode: II s'agit d'un essai comparatif, avec répartition aléatoire et échantillonnage en grappes, visant à comparer le rapport coût-efficacité de l'équipe supplémentaire avec celui d'équipes de triage formées uniquement de personnel infirmier, au service des urgences (SU), entre $8 \mathrm{~h}$ et $15 \mathrm{~h}$. Les coûts ne comprenaient que le salaire de l'équipe supplémentaire. Les revenus provenaient du programme de financement axé sur les résultats ainsi que du programme de paiement en fonction du nombre de patients et de la composition de la clientèle de I'Ontario. Le rapport coût-efficacité différentiel reposait sur le coût de l'équipe supplémentaire et sur trois paramètres, soit le coût 1) par patient supplémentaire examiné; 2) par heure gagnée relativement à l'évaluation initiale par le médecin et 3) par heure gagnée par rapport à la durée du séjour au SU. A aussi été déterminé le coût de substitution pour les patients. Quant à la satisfaction des patients, elle a été quantifiée sous forme de ratio coûts-avantages. Enfin, les auteurs ont réalisé une analyse de sensibilité en appliquant les coûts de l'équipe supplémentaire à différentes heures de travail, à différents salaires et à la disposition à payer.

Résultats: Le coût additionnel de l'équipe supplémentaire s'élevait à $3597,27 \$(1729,47 \$-\infty)$ par patient supplémentaire examiné; à 75,37 \$ $67,99 \$-105,30 \$)$ par heure gagnée relativement à l'évaluation initiale par le médecin et à 112,99\$ $(74,68 \$-251,43 \$)$ par heure gagnée par rapport à la durée du séjour au SU. Du point de vue de I'hôpital, le ratio coûtsavantages était de $38,6(19,0-\infty)$ et la valeur présente nette, de -447996 \$ (-435 646 \$ à -459 900 \$). Quant aux patients, le ratio coûts-avantages au regard de la satisfaction était de 2,8 $(2,3-4,6)$. Enfin, si le rendement de l'équipe supplémentaire était toujours appliqué de $12 \mathrm{~h}$ à $24 \mathrm{~h}$, la mesure serait plus rentable.

Conclusions: L'ajout d'une équipe d'aide au triage, formée d'infirmières et d'un médecin n'est pas une mesure rentable

From the *Department of Clinical Science and Education, Sodersjukhuset-Karolinska Institutet, Stockholm, Sweden; †Emergency Services, ‡Institute of Clinical Evaluative Sciences, and §HOPE Research Centre, Sunnybrook Health Sciences Centre, Toronto, ON; qDepartment of Family Medicine, Schulich School of Medicine and Dentistry, Western University, London, ON; and „Department of Learning, Informatics, Management, and Ethics, Solna-Karolinska Institutet, Stockholm, Sweden.

Correspondence to: Dr. Ivy Cheng, Sunnybrook Health Sciences Centre, C753-2075 Bayview Ave, Toronto, ON M4N 3M5; Email: ivy.cheng@ sunnybrook.ca

(C) Canadian Association of Emergency Physicians

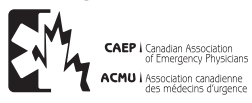

CJEM 2016;18(3):191-204

CJEM・JCMU

DOI 10.1017/cem.2015.88 
le jour, mais celle-ci semble plus facilement applicable durant les périodes de forte fréquentation, par exemple depuis la fin de la matinée jusqu'en soirée.
Keywords: Physician Triage, Senior Doctor Triage, Cost

Effective Analysis, System Evaluation, Emergency Department Administration, Emergency Department Crowding

\section{INTRODUCTION}

It is well established that prolonged emergency department length of stay (EDLOS) is associated with increased morbidity, mortality, ${ }^{1,2}$ decreased patient satisfaction, ${ }^{3,4}$ and increased left-without-being-seen (LWBS) rates. ${ }^{5}$ Additionally, prolonged EDLOS is expensive. In Canada, it was estimated that $\$ 51$ million dollars were spent on patients in 2005-2006 admitted through emergency departments (EDs) and waiting for a hospital bed. ${ }^{6}$ A study published in 2010 concluded that ED admission delays greater than 12 hours increased inpatient LOS at an annual additional cost of 2.1 million dollars. ${ }^{7}$ Owing to limited resources and increasing patient demand, the largest contributing factor to ED crowding is access block ${ }^{1}$ - the "diminished access to health care." 8 This multifactorial issue has no single solution, and its resolution will require a systems-approach rather than through the ED. Various solutions have been proposed to decrease $\operatorname{EDLOS}^{9-26}$; however, it remains unclear as to which solution is the most cost-effective.

In the province of Ontario, the problem of prolonged EDLOS came to the attention of the local government in 2006. The Ministry of Health and Long-Term Care, in concert with provincial representatives for the hospitals and physicians, convened an expert panel and provided 17 recommendations. ${ }^{27}$ In 2008, the Payfor-Results program was implemented, whereby hospitals were provided financial incentives to improve their EDLOS by $10 \%$ from the previous year until $\geq 90 \%$ of all ED patients reached target thresholds. ${ }^{28}$ For the institution studied, the 2009-2010 Payfor-Results target was to have $>=38 \%$ of admitted and $>=71 \%$ of discharged high-acuity patients (Canadian Triage Acuity Scale [CTAS] 1-3) with EDLOS $<=8$ hours. For discharged low-acuity patients (CTAS $4-5$ ), the target was to have $>=75 \%$ of patients with an EDLOS of $<=4$ hours. The 90th percentile target for physician-initial-assessment (PIA) time was set at 5 hours and 24 minutes, with an ideal target of 3 hours and 48 minutes. ${ }^{28,29}$ The duration between triage evaluation and assessment by the doctor was the PIA time. ${ }^{8}$
One approach proposed to decrease ED wait-times is the team approach to care ${ }^{29-32}$ or a front-line primary care team. A joint report by the major colleges in the United Kingdom recommended senior clinicians be present at the ED front door, ${ }^{33,34}$ and some hospitals in Australia ${ }^{35}$ and the United States have placed a physician at triage. ${ }^{36,37}$ But such an approach is perceived to be expensive ${ }^{38}$ given that ED costs are labor-driven and variable, and, consequently, marginal costs do not decrease as ED volumes increase. ${ }^{39}$ As a result, justification is required to increase manpower in the department. ${ }^{40}$ Some clinical studies have concluded that primary care teams improve outcomes at reasonable incremental costs ${ }^{41-43}$; however, no economic evaluations on team-based solutions to decrease EDLOS have yet been reported. Given our era of limited health resources, ${ }^{44}$ a rigorous determination of the cost-effectiveness of ED team-based solutions for LOS would help hospital administrators and decision makers decide whether implementation of a team-based approach to ED management is worth the expense.

The physician-nurse supplementary triage assessment team (MDRNSTAT) trial was a prospective, pragmatic, cluster randomized control trial over 26 weeks that compared a MDRNSTAT (intervention) to nurse-only triage (control) from 0800 to 1500 on weekdays and was published in $2013 .{ }^{29}$ This trial took place at Sunnybrook Hospital, a tertiary care academic centre located in Toronto, ON. It is a trauma, regional stroke, interventional cardiology, neurosurgical, and oncology centre with 348 acute care beds. In 2009, the number of patient visits to the ED was 45,405 per year with an admission rate of $22 \%$ with $80 \%$ CTAS $1-3$ patients (5\% CTAS 1). Access block was a significant issue with hospital occupancy typically exceeding $90 \%{ }^{45-47}$ and a median EDLOS for admitted patients of approximately 12 hours. By 2013, the number of visits increased to 58,518 with an admission rate of $22 \%$ and $88 \%$ of CTAS $1-3$ patients (4\% CTAS 1 ), and the number of acute beds decreased to 341. Hospital occupancy remained unchanged.

The MDRNSTAT intervention was found to significantly decrease median PIA time and median EDLOS for high $\left(\right.$ CTAS $^{48}$ 2-3) and low (CTAS 4-5) 
acuity, discharged patients not requiring a consultation. Consequently, morbidity, mortality, patient satisfaction, and expense-associated with prolonged EDLOS could be partially mitigated by such a program; however, its implementation consumes health care resources that could potentially be used elsewhere. The purpose of this study was to determine whether the implementation of MDRNSTAT was economically efficient from the perspective of a publicly funded hospital and the perspective of the patient.

\section{METHODS}

\section{Reference study}

The outcomes, EDLOS, PIA time, and LWBS rates were derived from the aforementioned cluster randomized-control trial comparing MDRNSTAT days (65 days, 3137 patients) with nurse-only triage days (66 days, 3163 patients). ${ }^{29}$ EDLOS was defined as the duration between triage arrival and departure from the ED. ${ }^{8}$ LWBS patients were those who left the ED before a medical exam was initiated. ${ }^{49}$

Control patients were triaged by the nurses, assigned a CTAS score, and directed into a patient care space or the waiting room if care spaces were not available. Triage-nurse orders were limited to basic lab investigations and electrocardiogram acquisition.

Intervention patients were similarly nurse-triaged. Those who had an immediate patient care space available were brought into the ED to wait for the emergency physician. When no patient care space was available, the patient was similarly placed in the waiting room. The MDRNSTAT would then select waiting room patients to assess in a triage assessment area, where a brief history and physical was performed. Selection of patients was at the team's discretion, but factors in the decision included wait-time, acuity, and necessity for physician time-sensitive decisions. The team initiated orders for diagnostic imaging (including CT or ultrasound), advanced lab work (e.g., D-dimer), treatment, consultation, and possible disposition. MDRNSTAT nurses initiated lab orders and carried out IV starts and treatment. If an assessment space became available in the ED, the patient's care was transferred to the regular emergency physician. Otherwise, the patient would be placed back in the waiting room. Patients were not blinded to the intervention but were unaware of which days the MDRNSTAT was working.

\section{Costs and revenue}

The analysis was conducted from the hospital and patient perspective. Because of the short time horizon with concrete costs, revenue, and outcome measures, we used a decision analysis and extrapolation model. The province of Ontario has a universal, publicly funded, government-run insurance system. For the hospital perspective, resources were based on personnel and diagnostic costs. Personnel costs were based on our hospital's physician and nurse hourly rates and Ministry of Health and Long-Term Care diagnostic imaging fees. Because capital costs, such as the physical plant, health professionals salaries and benefits, food, medication, and cost transfers were unchanged between the control and intervention groups, they were not included in the analysis. Costs and revenues were calculated in 2009 Canadian dollars $(\$ 1.00$ CAD $=$ \$0.87 USD, 2009 ${ }^{50}$ ).

In terms of ED resources, the Alternate Funding Agreement, Global Funding Program, and Payfor-Results programs collectively determine hospital revenue. The Alternate Funding Agreement prospectively funds the province's EDs based on the prior years' patient-volume seen and the case-mix of patients. In this program, a lump sum value is allocated to the hospital's ED for emergency physician salaries. Reconciliation payments for the current year are paid to an ED if actual patient volume exceeded what is allocated. Therefore, by decreasing the LWBS rate, Alternate Funding Agreement revenue is increased. The Global Funding Program is a fee-for-service model based on the Ontario Schedule of Benefits. ${ }^{51}$ In this program, for every service a physician provides for the patient, $38 \%$ of the cost of the service code value is flowed back to the physician. Therefore, by seeing more patients, revenue to the ED increases for both physicians and the institution. The Pay-for-Results program provides financial incentives to hospitals for achieving specific time threshold indicators. In 2009, reaching the 90th percentile PIA time target would reward the hospital $\$ 100,000$. Reaching acuity-based EDLOS targets for discharged and admitted patients would additionally reward the hospital $\$ 748,000$. Because the effectiveness outcomes were in the range of hours, discounting was not required. 


\section{Effectiveness outcomes}

This is a cost-effective analysis. ${ }^{52-54}$ Effectiveness outcomes were based on three intermediate outcomes: 1) the additional number of patients seen, 2) total hours saved for PIA time, and 3) EDLOS.

The trial's results were extrapolated to a MDRNSTAT staffed from 0800 to 1500 for the institution's ED patient volume of 45,405 patients during the 2009 calendar year. For this daytime period, 19,120 patients (42.1\% of annual volume) with $2.0 \%$ LWBS rate were seen. We projected the reference study's non-consulted, discharged CTAS 2-3 and CTAS 4-5 proportions to the corresponding 7 hours. We also analysed by hour of arrival with associated patient arrivals, LWBS rate, PIA-time, and EDLOS.

Extrapolating the LWBS-rate difference between intervention and control to the corresponding patient volume determined additional patients seen. Twosample, two-sided tests of proportions were carried out, and $95 \%$ confidence intervals were calculated around estimates.

For total EDLOS- or PIA-time saved, only statistically significant differences between intervention and control were used. Keeping the intervention LWBS rate of $1.5 \%$ and multiplying the corresponding patient volumes by their respective time differences determined total EDLOS time or PIA time saved between the control and intervention groups. Due to the nonparametric distribution of these measures, median differences and their associated confidence intervals were determined by the Hodges-Lehmann estimation method. This approach involves an analysis all pairwise differences between the two groups and to derive a median and associated $95 \%$ confidence interval around the differences.

\section{Cost-effectiveness and cost-benefit analysis-hospital perspective}

We conducted two comparative economic evaluations from the hospital perspective: 1) incremental costeffectiveness analysis and 2) incremental cost-benefit analysis. Direct cost and revenue generation by the MDRNSTAT was determined for 1 year. Revenue from the Alternate Funding Agreement, Global Funding Program, and reaching Pay-for-Results thresholds was determined by using study data extrapolated to the 2009 calendar year. Net values were calculated from the difference between cost and revenue. Incremental cost-effectiveness ratios were calculated by dividing net value over three different outcome measures: additional patients seen, PIA minutes saved, and EDLOS minutes saved. An incremental cost-benefit ratio (CBR) was determined by dividing the cost of the intervention by the revenue generated. Net present value was the cost subtracted from the revenue.

\section{Satisfaction analysis-patient perspective}

The literature suggests that a positive correlation exists between ED patient dissatisfaction, LWBS rates, and increased PIA times. ${ }^{5,55}$ Patient satisfaction was estimated by calculating the PIA time saved and additional patients seen between the intervention and control groups. For the cost-benefit analyses, willingness-to-pay values ${ }^{56}$ to decrease ED wait-times are preferred; however, Canadian data have not been determined. An alternative uses the human capital approach, ${ }^{56}$ where wait-times are an opportunity cost of lost wages, irrespective of employment status. We used the 2009 Canadian minimum wage as a financial surrogate for patient valuation of wait-times. Based on a 2012 hourly wage of $\$ 24.38^{57}$ with $1.9 \%$ annual inflation, it was estimated that the 2009 hourly rate was $\$ 23.02$. By multiplying PIA time saved with hourly wage and additional patients seen by daily wage, a value for patient satisfaction was determined. Dividing the gross MDRNSTAT cost by patient satisfaction value provided a CBR.

\section{Satisfaction analysis—staff perspective}

Three non-MDRNSTAT emergency physicians, three non-MDRNSTAT nurses, a MDRNSTAT physician, and a nurse completed a survey after each shift. The survey queried whether staff felt that the MDRNSTAT provided better patient quality of care, benefited patient flow, contributed to teamwork and collegiality, or improved personal efficiency. This was determined using a 7-point Likert Scale, ranging 1 (strongly disagree) to 7 (strongly agree).

\section{Sensitivity analysis}

By changing the MDRNSTAT working time period and salary, we performed a univariate sensitivity analyses to determine the most cost-efficient period for the team. We extrapolated study data to the 
corresponding patient volumes and LWBS rates between 1600 and 2400 (8 hours), 1200 to 0600 (18 hours), and 1200 to 2400 (12 hours) (Figure 1). MDRNSTAT salary was decreased from $\$ 180 / \mathrm{hr}$ to $\$ 100 / \mathrm{hr}$. In 2009, the LWBS rate was $6.2 \%$.

For patients, we used willingness-to-pay values from a Dutch study ${ }^{58}$ on valuation of wait-times for nonemergent orthopedic assessment or non-palliative radiotherapy. We performed the cost-effective analysis and patient flow graphs with Microsoft Excel (Version 14.4.1, Microsoft Corporation, Redmond, WA). Stata (Version 13.1, StataCorp, College Station, TX) was used to carry out the hourly cost-effective analysis and produce sensitivity graphs.

\section{RESULTS}

\section{Primary analysis}

In 2009, 75.8\% (62.8\% non-consulted, discharged) and $19.6 \%(89.8 \%$ non-consulted, discharged) of all patients seen at the study location were CTAS 2-3 and CTAS 4-5, respectively. The MDRNSTAT directly saw $24.7 \%$ and $20.2 \%$ of the CTAS 2-3 and CTAS 4-5, respectively. Table 1 provides outcomes of the original trial of the MDRNSTAT and illustrates interventions, such as lab orders, diagnostic imaging, consultations, and admissions were similarly distributed between the two groups. Compared to controls, the MDRNSTAT group had a significantly decreased PIA time and EDLOS for non-consulted discharged patients. For patients who were discharged, the MDRNSTAT was associated with decreased lab work, diagnostic imaging, and consult time. For patients who were admitted, lab work and diagnostic imaging request time were significantly decreased in the MDRNSTAT group. Table 2 shows the cost and hospital revenue of the MDRNSTAT compared to the control group. Revenue was achieved by decreasing the number of LWBS patients through government funding programs.

Table 3 provides the intermediate effectiveness outcomes (increased number of patients seen, PIA time, and EDLOS) from the hospital perspective. The intervention cost was $\$ 3,597.27$ (CI: $\$ 1,729.47$ to $\infty$ ) per additional-patient-seen from 0800 to 1500 (Figure 2). Keeping the LWBS constant at $1.5 \%$, the intervention cost \$75.37/PIA hour saved (CI: \$67.99 to $\$ 105.30$ ) (Figure 3) and $\$ 112.99 /$ EDLOS hour saved (CI: $\$ 74.68$ to $\$ 251.43$ ) (Figure 4). The hospital CBR was 38.6 (CI: 19.0 to $\infty$ ).

Table 4 provides the cost-effective analysis by hour of arrival. From 1900 to 2400, the intervention cost less than $\$ 510$ per additional patient seen. Between 1200 and 0200, the cost per PIA hour saved was less than $\$ 100.00$. For EDLOS, the cost per hour saved remained less than $\$ 120$ for 1200 to 1900 and 2300 to 0100 .

Table 5 provides patient satisfaction information. The MDRNSTAT was associated with a decrease in

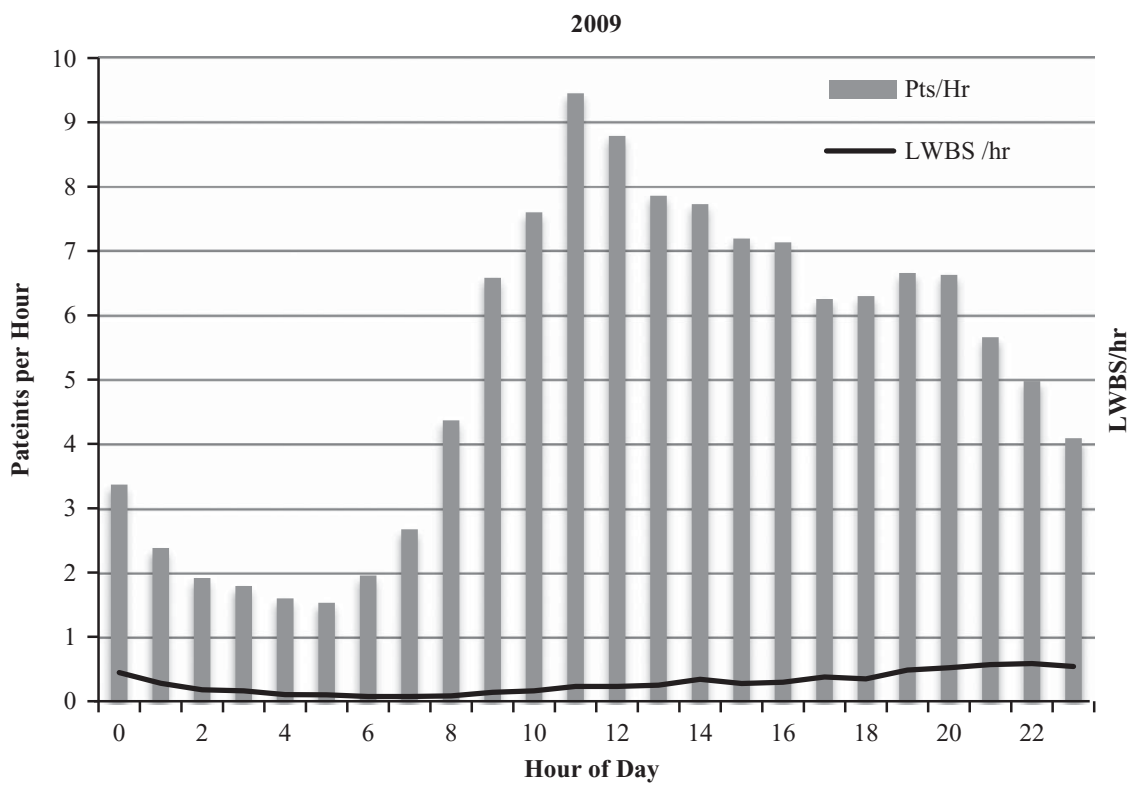

Figure 1. Plots the number of patient arrivals and left-without-being-seen (LWBS) rate by hour of day starting from 2400 from January 1 to December 31, 2009. The 2009 LWBS rate was $6.2 \%$. 
Table 1. Outcomes of the original trial of a physician-nurse supplementary triage assistance team (MDRNSTAT)

\begin{tabular}{|c|c|c|c|}
\hline Outcome & \multicolumn{2}{|c|}{$E P+M D R N S T A T$} & Control \\
\hline $\mathrm{n}$ & \multicolumn{2}{|c|}{3137} & 3163 \\
\hline \multicolumn{4}{|l|}{ Resource Utilization } \\
\hline Bloodwork request & \multicolumn{2}{|c|}{$44.7 \%$} & $45.3 \%$ \\
\hline Diagnostic imaging request & \multicolumn{2}{|c|}{$56.5 \%$} & $57.4 \%$ \\
\hline Consultations & \multicolumn{2}{|c|}{$18.6 \%$} & $19.7 \%$ \\
\hline Admissions & \multicolumn{2}{|c|}{$19.3 \%$} & $18.5 \%$ \\
\hline \multicolumn{4}{|l|}{ Pay-for-Results Targets } \\
\hline 90th\% Physician-initial-assessment time (hrs:min, $<=3: 48$ ) & \multicolumn{2}{|c|}{ 3:31 } & $4: 25$ \\
\hline Discharged CTAS 2-3 P4R target $(<=8 \mathrm{hr}, 71 \%)$ & \multicolumn{2}{|c|}{$84.9 \%$} & $81.3 \%$ \\
\hline Discharged CTAS 4-5 P4R target $(<=4 \mathrm{hr}, 75 \%)$ & \multicolumn{2}{|c|}{$80.6 \%$} & $81.9 \%$ \\
\hline Admission P4R target $(<=8 \mathrm{hr}, 38 \%)$ & \multicolumn{2}{|c|}{$23.3 \%$} & $21.3 \%$ \\
\hline Time & EP & MDRNSTAT & Control \\
\hline$n$ & 2387 & 750 & 3163 \\
\hline Physician-initial-assessment time & $1: 13$ & $0: 25$ & $1: 21$ \\
\hline Difference (minutes) from control $[95 \% \mathrm{Cl}]$ & $-7[-3$ to -10$]$ & $-53[-48$ to -57$]$ & \\
\hline \multicolumn{4}{|l|}{ Discharged CTAS 2-3 EDLOS (hrs:min) } \\
\hline Consulted & 7:06 & $6: 25$ & $7: 19$ \\
\hline Difference (minutes) from control $[95 \% \mathrm{Cl}]$ & $-35[-73$ to 3$]$ & $-52[-106$ to 2$]$ & \\
\hline Non-consulted & 4:07 & 4:01 & $4: 29$ \\
\hline Difference (minutes) from control $[95 \% \mathrm{Cl}]$ & $-19[-7$ to -31$]$ & $-34[-52$ to -16$]$ & \\
\hline \multicolumn{4}{|l|}{ Discharged CTAS 4-5 EDLOS (hrs:min) } \\
\hline Consulted & $4: 40$ & $4: 19$ & $4: 57$ \\
\hline Difference (minutes) from control [95\% Cl] & $7[-65$ to 78$]$ & $-18[-188$ to 153$]$ & \\
\hline Non-consulted & $2: 08$ & $1: 10$ & 2:06 \\
\hline Difference (minutes) from control $[95 \% \mathrm{Cl}]$ & $3[-7$ to 13$]$ & $-52[-65$ to -38$]$ & \\
\hline Admissions EDLOS & $11: 41$ & $11: 20$ & $12: 03$ \\
\hline Difference (minutes) from control $[95 \% \mathrm{Cl}]$ & $-16[-63$ to 32$]$ & $-38[-102$ to 26$]$ & \\
\hline \multicolumn{4}{|l|}{ Discharge Processes } \\
\hline Lab work request time & $1: 42$ & 1:02 & $1: 47$ \\
\hline Difference (minutes) from control [95\% Cl] & $-3[-12$ to 6$]$ & $-32[-44$ to -21$]$ & $2: 16$ \\
\hline Diagnostic imaging request time & $1: 56$ & $0: 51$ & $3: 20$ \\
\hline Difference (minutes) from control [95\% Cl] & $-18[-27$ to -9$]$ & $-67[-79$ to -55$]$ & \\
\hline Consult Request Time & $2: 59$ & $2: 24$ & \\
\hline Difference (minutes) from control $[95 \% \mathrm{Cl}]$ & $-14[-34$ to 6$]$ & $-55[-82$ to -27$]$ & \\
\hline \multicolumn{4}{|l|}{ Admission Processes } \\
\hline Lab work request time & $1: 51$ & 1:07 & $1: 38$ \\
\hline Difference (minutes) from control [95\% Cl] & $4[-9$ to 16$]$ & $-20[-37$ to -3$]$ & $2: 41$ \\
\hline Diagnostic imaging request time & $2: 43$ & 1:05 & $3: 57$ \\
\hline Difference (minutes) from control $[95 \% \mathrm{Cl}]$ & $-10[-26$ to 6$]$ & $-87[-109$ to -64$]$ & $7: 41$ \\
\hline Consult request time & $3: 49$ & $3: 36$ & \\
\hline Difference (minutes) from control [95\% Cl] & $-5[-24$ to 15$]$ & $-23[-48$ to 3$]$ & \\
\hline Bed request time & 7:30 & 7:01 & \\
\hline Difference (minutes) from control [95\% Cl] & $-8[-34$ to 7$]$ & $-29[-66$ to 7$]$ & \\
\hline LWBS rate & $1.8 \%$ & $0.5 \%$ & $2.2 \%$ \\
\hline Difference (\%) from control $[95 \% \mathrm{Cl}]$ & $-0.3 \%[-0.4$ to 1.0$]$ & $-1.6 \%[-0.9$ to -2.4$]$ & \\
\hline LWBS rate & & & $2.2 \%$ \\
\hline Difference (\%) from control $[95 \% \mathrm{Cl}]$ & -0.7 & $-1.3 \%]$ & \\
\hline
\end{tabular}

CTAS = Canadian Triage Acuity Scale; EDLOS = emergency department length of stay; EP-scheduled emergency physician is initial physician seen; LWBS = left without being seen; MDRNSTAT-team is initial physician seen; P4R = Pay-for-Results. 
Cost-effectiveness of a physician-nurse triage team

Table 2. Cost and revenue of the MDRNSTAT and control group: base study and sensitivity analysis

\begin{tabular}{|c|c|c|c|c|c|c|}
\hline \multirow[b]{2}{*}{ MDRNSTAT Working Hours } & \multirow[b]{2}{*}{ MDRNSTAT Hourly Rate } & \multirow[b]{2}{*}{ MDRNSTAT Annual Cost } & \multicolumn{4}{|c|}{ Revenue } \\
\hline & & & AFP & GFP & PIA & NPV \\
\hline 0800-1500 (base rate)* & $\$ 180 / h r$ & $\$ 459,900$ & $\$ 10,354$ & $\$ 1,550$ & $\$ 0$ & $\$ 447,996$ \\
\hline 0800-1500 (reduced rate) & $\$ 100 / \mathrm{hr}$ & $\$ 255,500$ & & & & $\$ 243,596$ \\
\hline $1600-2400$ (base rate) & $\$ 180 / h r$ & $\$ 525,600$ & $\$ 70,651$ & $\$ 10,513$ & $\$ 0$ & $\$ 444,436$ \\
\hline 1600-2400 (reduced rate) & $\$ 100 / \mathrm{hr}$ & $\$ 292,000$ & & & & $\$ 210,836$ \\
\hline 1200-0600 (18 hrs, base rate) & $\$ 180 / \mathrm{hr}$ & $\$ 1,182,600$ & $\$ 177,364$ & $\$ 26,392$ & $\$ 100,000$ & $\$ 878,845$ \\
\hline 1200-0600 (18 hrs, reduced rate) & $\$ 100 / \mathrm{hr}$ & $\$ 657,000$ & & & & $\$ 353,245$ \\
\hline $1200-2400$ (base rate) & $\$ 180 / \mathrm{hr}$ & $\$ 788,400$ & $\$ 177,364$ & $\$ 26,392$ & $\$ 100,000$ & $\$ 484,645$ \\
\hline $1200-2400$ (reduced rate) & $\$ 100 / \mathrm{hr}$ & $\$ 438,000$ & & & & $\$ 134,245$ \\
\hline
\end{tabular}

Table 3. Hospital perspective on intermediate effectiveness outcomes between intervention and control

\begin{tabular}{|c|c|c|c|c|c|}
\hline & \multirow[b]{2}{*}{ Patient Volume } & \multirow[b]{2}{*}{ LWBS \% } & \multicolumn{3}{|c|}{ Intervention (MDRNSTAT) v. Control } \\
\hline & & & Patients Seen Difference & PIA Hrs Difference & EDLOS Hrs Difference \\
\hline 0800-1500 (Base) & 19,120 & $2.2 \%$ & $125[0-252]$ & $6,102[4,368-6,764]$ & $4,070[1,829-6,158]$ \\
\hline $1600-2400$ & 17,410 & $6.4 \%$ & 845 [770-919] & $5,556[3,977-6,159]$ & $3,706[1,666-5,607]$ \\
\hline $1200-0600$ (18 hrs) & 33,527 & $6.2 \%$ & $2,120[1,925-2,315]$ & $10,700[7,659-11,861]$ & $7,137[3,207-10,798]$ \\
\hline $1200-2400$ & 28,934 & $6.2 \%$ & $2,120[1,925-2,315]$ & $9,234[6,632-10,236]$ & $6,160[2,768-9,319]$ \\
\hline
\end{tabular}

the time to see a physician of 6,102 hours and 996 hours of saved opportunity cost for 124 LWBS patients. Applying the LWBS rate of $1.5 \%$ with a Canadian minimum wage of $\$ 23.02$ as a surrogate for patient satisfaction, the CBR was 2.8 (2.3 to 4.6) (Figure 5).

The MDRNSTAT and non-MDRNSTAT emergency physicians and nurses completed 162 and 551 surveys, respectively. Compliance was $99.7 \%$. Staff generally indicated that the MDRNSTAT provided better patient quality of care, benefited patient flow, and improved personal efficiency. Staff also strongly indicated that the MDRNSTAT contributed to teamwork and collegiality.

\section{Sensitivity analysis}

We extrapolated our study results to three different time periods: 1600 to 2400,1200 to 0600 , and 1200 to 2400. Each period had different LWBS rates and PIA times. During the 1600 to 2400 shifts, the LWBS rate was $6.4 \%$. Keeping the intervention LWBS rate at $1.5 \%$, the cost per additional patient seen was $\$ 526.20$ (\$475.61 to \$586.63), \$94.59/PIA hour saved (\$85.34 to $\$ 132.16), \$ 141.81 /$ EDLOS hour saved (\$93.74 to $\$ 315.57$ ), and the CBR was 6.5 (6.0 to 7.1). The patient satisfaction CBR was 1.8 (1.7 to 2.2).

From 1200 to 0600 the following day (18 hours), our ED exceeded the ideal Pay-for-Performance PIA target of 3 hours and 48 minutes. LWBS rates progressively exceeded $2.4 \%$ by 1200 and peaked at $13 \%$ by 2400 , and dropped to $3.6 \%$ by 0500 (see Figure 1). Annual LWBS rate was $6.2 \%$. Assuming that MDRNSTAT working from 1200 to 0600 would achieve the Payfor-Performance PIA target and decrease the annual LWBS rate to $1.5 \%$, the intervention would cost $\$ 414.50$ per additional patient seen (\$371.47 to 466.22), $\$ 101.18 /$ PIA hour saved (\$91.28 to $\$ 141.36$ ), and $\$ 165.69 /$ EDLOS hour saved (\$109.52 to $\$ 368.70$ ). Hospital CBR was 3.9 (3.7 to 4.1). Patient satisfaction CBR was 1.9 (1.7 to 2.2). 


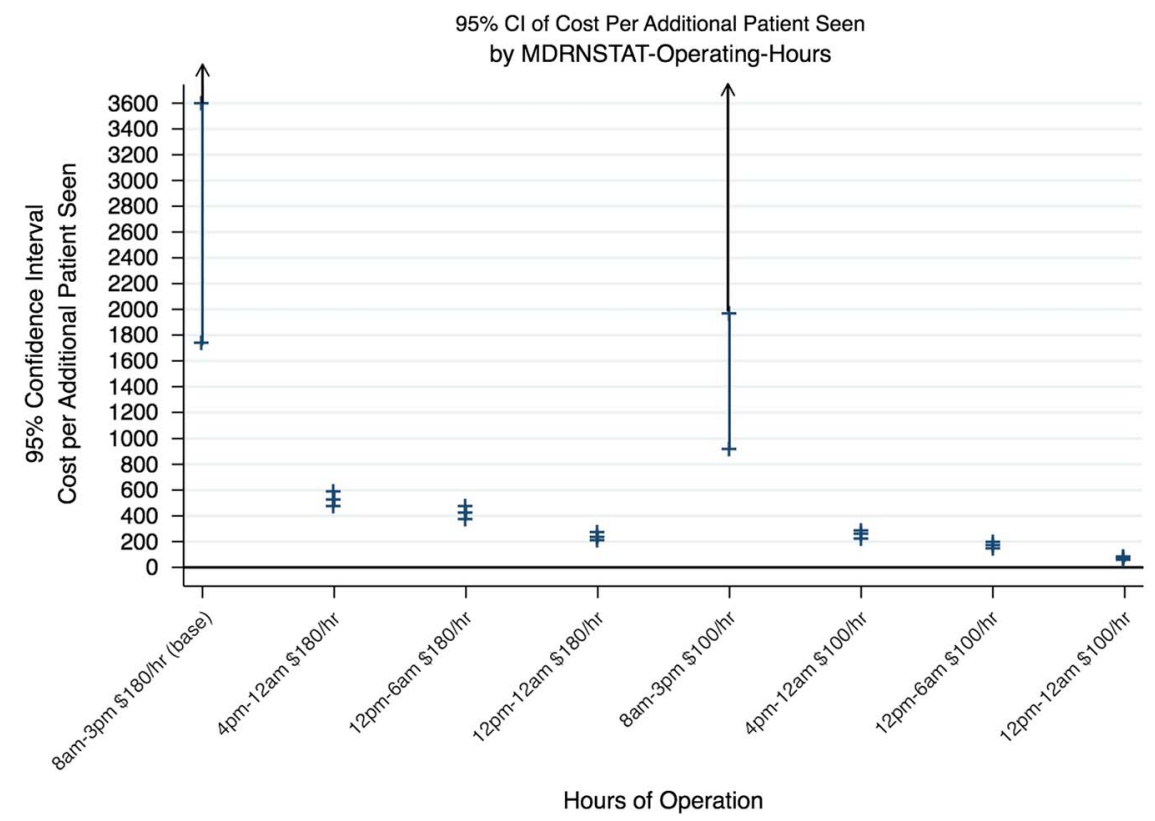

Figure 2. Plots the $95 \%$ confidence interval of the cost per additional patient seen by MDRNSTAT operating hours of 0800 to 1500 (base), 1600 to 2400,1200 to 0600 the following day, and 1200 to 2400 at salary rates of $\$ 180 /$ hour and $\$ 100 /$ hour.

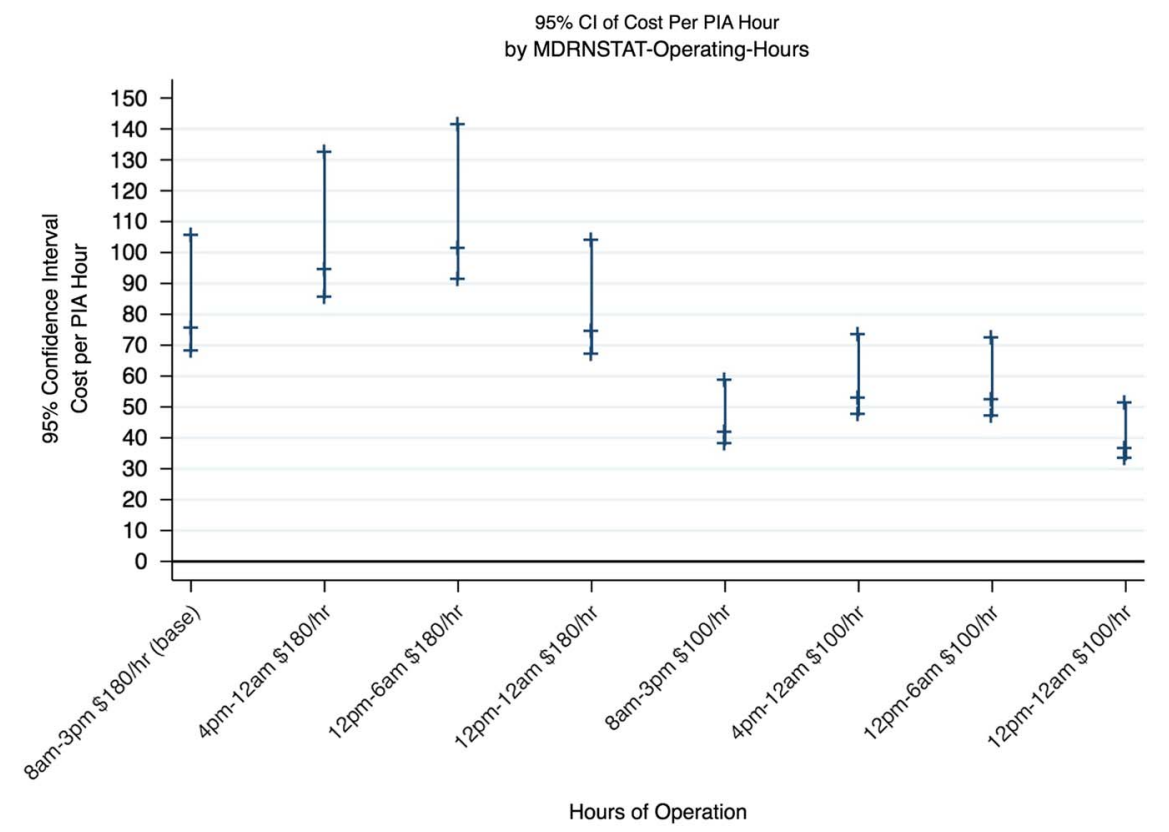

Figure 3. Plots the $95 \%$ confidence interval of the cost per physician initial assessment (PIA) hour saved by MDRNSTAT operating hours of 0800 to 1500 (base), 1600 to 2400,1200 to 0600 the following day, and 1200 to 2400 at salary rates of $\$ 180 /$ hour and $\$ 100 /$ hour.

We hypothesized that the MDRNSTAT working from 1200 to 2400 could achieve the same outcomes as working from 1200 to 0600 . If so, the intervention would cost $\$ 228.58$ per additional patient seen $(\$ 201.21$ to \$261.46), \$74.55/PIA hour saved (\$67.25 to $\$ 103.81$ ), and $\$ 129.39 /$ EDLOS hour saved (\$84.60 to \$284.82). Hospital CBR was 2.6 (2.4 to 2.8). Patient satisfaction CBR was 1.3 (1.2 to 1.6$)$. 


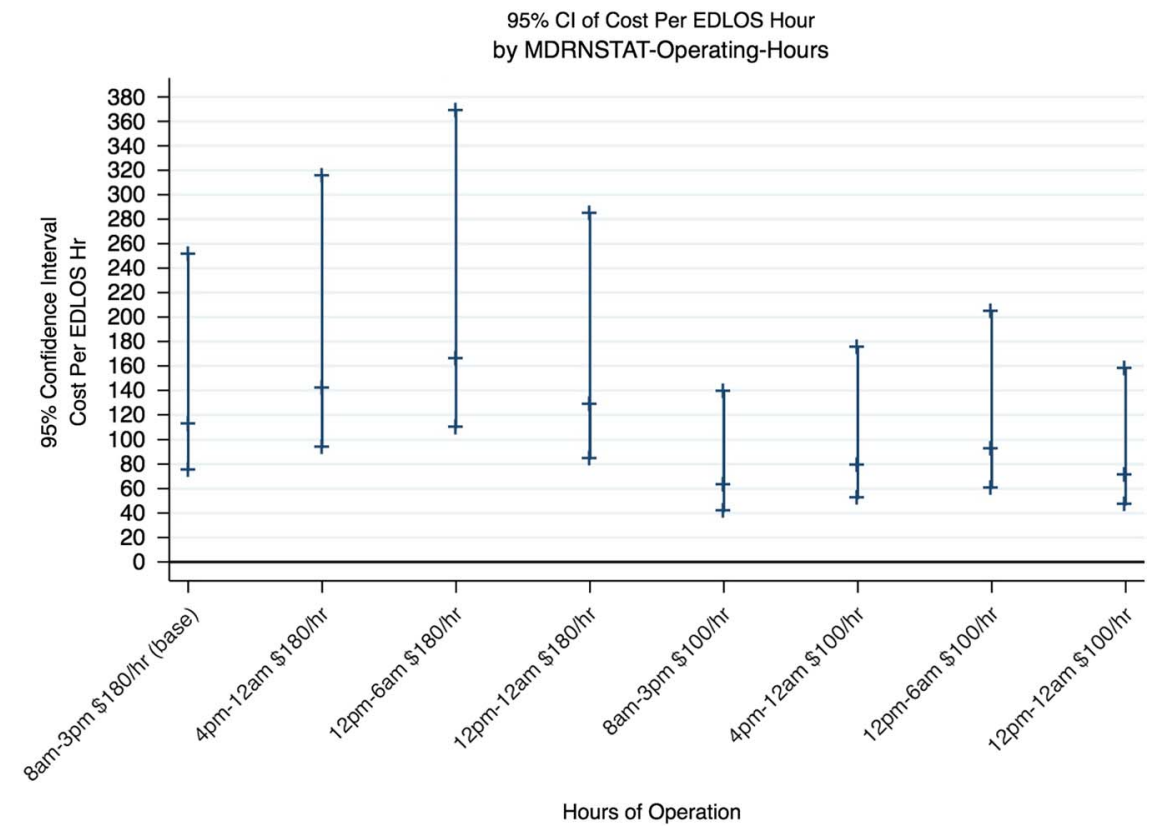

Figure 4. Plots the $95 \%$ confidence interval of the cost per emergency department length of stay (EDLOS) hour saved by MDRNSTAT operating hours of 0800 to 1500 (base), 1600 to 2400,1200 to 0600 the following day, and 1200 to 2400 at salary rates of $\$ 180 /$ hour and $\$ 100 /$ hour.

From the hospital perspective, our analyses were replicated based on a salary of $\$ 100 / \mathrm{hr}$. The sensitivity analysis for cost per additional patient seen, PIA hour saved, EDLOS hour saved, and CBR is summarized in Figures 2, 3, and 4. For patient satisfaction, the Dutch value treatment waiting time at $€ 30.10$ per hour $(\$ 45.83$ $\mathrm{CAD})^{58}$ resulting with a CBR $<1$ from 1200 to 2400. Results of this sensitivity analysis are provided in Table 5 and Figure 5.

\section{DISCUSSION}

We found that the MDRNSTAT program was associated with a significant decrease in ED wait times for non-consulted, discharged patients and a decrease in the number of LWBS patients in an academic tertiary level hospital. The cost and revenue drivers for this team were salary, hours worked, and pay-for performance schemes. In the absence of access block or financial wait-time incentives, low LWBS rates, or high manpower costs, the MDRNSTAT would not be costeffective. Because access block, patient arrivals, LWBS rates, and PIA times increase from 1200 onward, it appears that implementing such a program from 1200 to 2400 would be more cost-effective than 0800 to 1500 . Lowering salaries or having only physiciantriage $^{35}$ would reduce manpower costs. Physician and nurse salaries vary internationally, ${ }^{59}$ so MDRNSTAT would be more cost-effective in countries with lower hourly rates. In countries such as Australia, physicians are capable of performing all of the MDRNSTAT duties. By eliminating the nurse, the physician-triage role would be more cost-efficient. Reduction of manpower costs could be achieved by using delegated orders; however, it is uncertain whether quality of care or patient satisfaction outcomes in such an approach would be equivalent. Regarding patient satisfaction, the team appears more cost-effective during prolonged PIA times and LWBS rates. Consequently, working at 1200 to 2400 would be more cost-effective than working at 0800 to 1500 .

There were limitations in our study. This was a cost-effectiveness study using intermediate outcomes rather than metrics such as quality-adjusted-life years (QALY) or mortality end points. A cost-utility analysis, with a formalized measurement of QALYs, patient satisfaction, or willingness-to-pay would be superior.

In the sensitivity analysis, the assumption we made that the MDRNSTAT working from 1200 to 2400 would achieve an annual $1.5 \%$ LWBS rate could be questioned. However, from 0600 to 1200 , LWBS rates and PIA times were less than $2 \%$ and below the PIA target of 3 hours and 48 minutes, so a MDRNSTAT would not be required. From 1200 to $2400,60 \%$ of the 


\begin{tabular}{|c|c|c|c|c|c|c|c|c|}
\hline $\begin{array}{l}\text { Hour of } \\
\text { Arrival }\end{array}$ & $\begin{array}{c}\text { Patients/ } \\
\mathrm{Hr}\end{array}$ & $\begin{array}{c}\text { LWBS/ } \\
\mathrm{Hr}\end{array}$ & $\begin{array}{l}\text { PIA Time } \\
\text { Median (Hrs) }\end{array}$ & $\begin{array}{c}\text { CTAS 2-3 EDLOS } \\
\text { Median (Hrs) }\end{array}$ & $\begin{array}{c}\text { CTAS 4-5 EDLOS } \\
\text { Median (Hrs) }\end{array}$ & Cost/ Patient Seen & Cost/ PIA Hr Saved & Cost/ EDLOS Hr Saved \\
\hline 0 & 3.5 & 0.36 & 2.1 & 5.5 & 4.1 & $\$ 485.34$ [\$458.35-515.06] & $\$ 51.51$ [\$49.33-53.35] & $\$ 73.49[\$ 65.44-85.27]$ \\
\hline 2 & 2.0 & 0.17 & 2.2 & 5.3 & 3.7 & $\$ 1194.92[\$ 1120.49-1279.06]$ & $\$ 86.89$ [\$83.29-89.93] & $\$ 141.54$ [\$123.56-169.38] \\
\hline 3 & 2.1 & 0.18 & 1.7 & 5.1 & 4.2 & $\$ 1090.46[\$ 1023.61-1165.80]$ & $\$ 149.86$ [\$138.89-159.73] & $\$ 163.08$ [\$140.53-199.28] \\
\hline 4 & 1.7 & 0.17 & 1.7 & 5.2 & 4.9 & $\$ 1161.08$ [\$1098.69-1230.35] & $\$ 171.61$ [\$159.78-182.16] & $\$ 167.05$ [\$145.79-199.95] \\
\hline 7 & 2.6 & 0.03 & 1.5 & 4.5 & 2.8 & NS & $\$ 146.07$ [\$132.32-159.01] & $\$ 275.37$ [\$198.75-484.28] \\
\hline 8 & 4.4 & 0.06 & 0.9 & 3.7 & 1.9 & NS & NS & NS \\
\hline 9 & 6.7 & 0.04 & 0.8 & 3.5 & 1.7 & NS & NS & NS \\
\hline 10 & 7.7 & 0.07 & 0.9 & 3.9 & 1.8 & NS & NS & NS \\
\hline 11 & 9.7 & 0.15 & 1.2 & 4.0 & 2.1 & NS & $\$ 108.02[\$ 84.19-138.77]$ & NS \\
\hline 12 & 9.6 & 0.23 & 1.7 & 4.5 & 2.6 & $\$ 2146.63$ [\$1387.99-4492.61] & $\$ 28.63[\$ 26.68-30.37]$ & $\$ 77.93$ [\$56.15-137.49] \\
\hline 13 & 8.1 & 0.30 & 2.0 & 4.6 & 2.7 & $\$ 917.42[\$ 751.01-1165.32]$ & $\$ 23.67$ [\$22.53-24.65] & $\$ 73.88$ [\$57.15-109.78] \\
\hline 14 & 8.2 & 0.26 & 2.2 & 5.0 & 2.7 & $\$ 1248.71$ [\$968.35-1729.64] & $\$ 20.17$ [\$19.32-20.89] & $\$ 47.66$ [\$39.87-60.90] \\
\hline 15 & 7.7 & 0.28 & 2.1 & 5.0 & 2.7 & $\$ 1029.88$ [\$836.02-1325.59] & $\$ 23.60[\$ 22.51-24.52]$ & $\$ 46.71$ [\$39.59-58.43] \\
\hline 16 & 7.1 & 0.25 & 1.9 & 4.8 & 2.9 & $\$ 1170.64$ [\$948.07-1513.86] & $\$ 30.88$ [\$29.21-32.34] & $\$ 71.75$ [\$57.99-97.58] \\
\hline 17 & 6.9 & 0.32 & 1.9 & 4.9 & 2.9 & \$758.94 [\$653.47-898.97] & $\$ 30.98$ [\$29.34-32.39] & $\$ 63.45[\$ 52.20-83.61]$ \\
\hline 18 & 6.7 & 0.25 & 1.8 & 4.5 & 3.0 & $\$ 1127.75$ [\$926.81-1426.97] & $\$ 34.09$ [\$32.15-35.79] & $\$ 110.13$ [\$80.52-187.23] \\
\hline 19 & 6.8 & 0.41 & 1.9 & 4.7 & 2.6 & $\$ 500.19[\$ 447.70-563.89]$ & $\$ 31.13[\$ 29.42-32.51]$ & $\$ 79.78$ [\$62.63-114.99] \\
\hline 20 & 6.9 & 0.43 & 1.9 & 4.2 & 2.7 & $\$ 453.16$ [\$407.34-508.15] & $\$ 31.68$ [\$29.99-33.14] & $\$ 557.57$ [\$494.44-616.60] \\
\hline 21 & 5.8 & 0.41 & 1.9 & 4.0 & 2.6 & $\$ 473.23[\$ 431.32-522.38]$ & $\$ 37.03[\$ 35.08-38.70]$ & $\$ 735.83$ [\$644.80-822.97] \\
\hline 22 & 5.1 & 0.39 & 1.8 & 4.3 & 2.3 & $\$ 476.77$ [\$439.77-519.27] & $\$ 53.29[\$ 48.89-56.28]$ & $\$ 958.25$ [\$810.83-1109.56] \\
\hline 23 & 4.0 & 0.36 & 1.8 & 5.2 & 2.8 & $\$ 508.50$ [\$475.74-545.26] & $\$ 64.61$ [\$60.74-68.00] & $\$ 74.44$ [\$64.56-89.94] \\
\hline
\end{tabular}




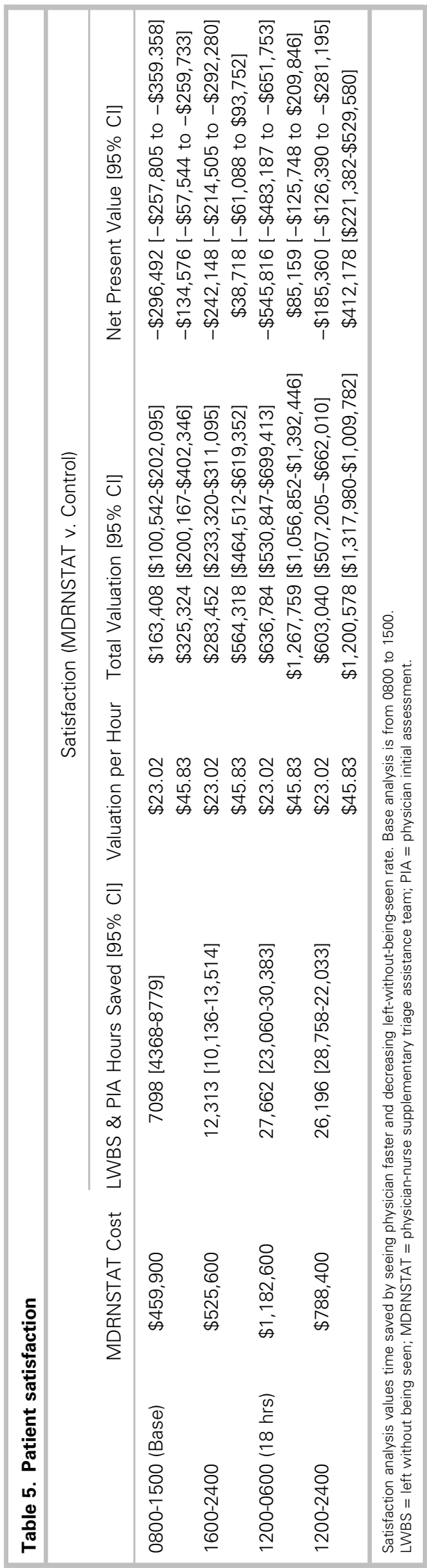

daily volume arrived. From 2400 to $0600,10 \%$ of the patient volume arrived. High LWBS rates from 2400 to 0600 likely arise from long wait-times secondary to the 1200 to 2400 patient volume backlog being cleared after 2400. If the MDRNSTAT efficiently managed patient flow from 1200 to 2400, this backlog would likely be eliminated, and working from 2400 to 0600 would not be required. A future study of MDRNSTAT working 1200 to 2400 would be beneficial.

The generalizability of our study is limited by the fact that our results arise from a single-centre tertiary academic centre with a complex patient population. ${ }^{29}$ Most public academic hospitals are supported by public insurance plans with unique funding models; therefore, our results may not be generalizable to other health systems and jurisdictions. However, hospitals using a case-mix, volume-based, fee-for-service, or payfor-performance funding schemes should find this analysis useful. A future multicentre study, with different funding models and a MDRNSTAT working during the hours of high patient flow, would be ideal. Additionally, a larger study population would allow the determination of whether significant mortality differences exist. To assess morbidity, longer term and regional follow-up is required. We used a positivist approach investigating a single intervention for tackling the problem of wait-times. Given the complexity of factors and multiple numbers of stakeholders involved in prolonged ED wait-times, a relativist, systemsthinking approach may be preferable. ${ }^{60,61}$

Prolonged PIA times and LWBS rates are associated with decreased patient satisfaction. However, for patients who are not employed, hourly wages may not accurately represent a patient's willingness to pay to decrease wait-times. The Dutch study surveyed patients who were not working and were waiting for nonemergent orthopedic, non-palliative radiation treatment or rehabilitation. ${ }^{58} \mathrm{We}$ applied the value arising from this research ( $€ 30.10=\$ 45.83 \mathrm{CAD}$ ) in our sensitivity analysis. However, it is arguable that this value underestimates ED waiting time. Many patients seek care for perceived emergent problems, such as pain. As a result, their expectations of quick resolution of the presenting complaint may be higher. At our institution, $40 \%$ of patients arrive with a complaint of pain. Additionally, we may have underestimated the gains in PIA time in our sensitivity analysis by extrapolating study data to the other time intervals. The median control PIA time for 


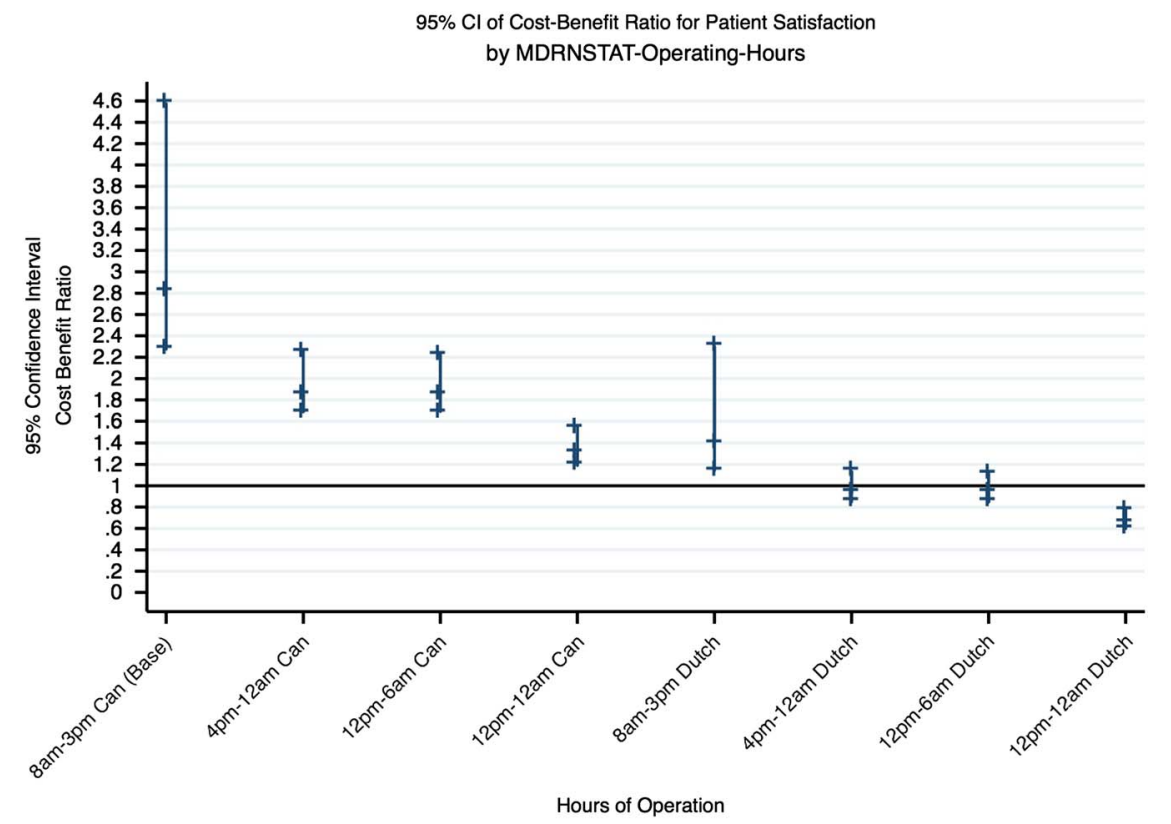

Figure 5. Plots the $95 \%$ confidence interval of the cost-benefit ratio for patient satisfaction by MDRNSTAT operating hours of 0800 to 1500 (base), 1600 to 2400, 1200 to 0600 the following day, and 1200 to 2400 at salary rates of $\$ 180 /$ hour. CanCanadian minimum wage (\$23.02), Dutch-Dutch valuation of waiting time for treatment $(\$ 45.83)$.

the study was 1 hour and 21 minutes, but from 1200 to 0600, the median PIA was 1 hour and 54 minutes. For the study period, the maximum PIA time was 9 hours and 15 minutes.

Our results indicate that MDRNSTAT decreases waiting in the front lines of the ED and is unable to mitigate access block to hospital admission. It could be argued that the cost of such a team would be better spent on access block solutions. Future cost-effectiveness analyses comparing the MDRNSTAT with access block interventions may be warranted. Although concerns could be raised that the MDRNSTAT provides suboptimal care because patients are not seen in traditional care spaces; however, our original study did not identify any harm from this program.

This is the first study to investigate the cost-effectiveness of the MDRNSTAT strategy. A number of studies have investigated only costs and found that personnel and construction of patientcare areas are expensive. ${ }^{32,38}$ Revenue gained by seeing more patients is dependent upon the patient remuneration system. In systems that provide even more robust remuneration than the Alternate Funding Agreement, Global Funding Program, and Pay-for-Results systems, the costs of such a team could be offset.

\section{CONCLUSION}

The MDRNSTAT is not a cost-effective daytime strategy but appears to be more feasible during time periods with higher patient volume, such as late morning to evening. ED administrators need to be thoughtful on whether a MDRNSTAT could be effectively used in their department. Factors to consider include patient arrival rates, LWBS reduction, physician satisfaction, and impact on patient wait-times. The need for cost-effectiveness research on patient-flow strategies and quality interventions has never been greater. With information arising from such research, administrators could make more evidence-informed ED operational decisions.

Competing interests: The authors acknowledge financial support from AFP (Alternative Funding Plan) Innovation Fund.

\section{REFERENCES}

1. Forero R, Hillman KM, McCarthy S, et al. Access block and ED overcrowding. Emerg Med Australas 2010;22(2):119-35.

2. Guttmann A, Schull MJ, Vermeulen MJ, et al. Association between waiting times and short-term mortality and hospital admission after departure from emergency department: 
population based cohort study from Ontario, Canada. BM7 2011;342:d2983.

3. Boudreaux ED, D'Autremont S, Wood K, et al. Predictors of emergency department patient satisfaction: stability over 17 months. Acad Emerg Med 2004;11(1):51-8.

4. Soremekun OA, Takayesu JK, Bohan SJ. Framework for analyzing wait times and other factors that impact patient satisfaction in the emergency department. 7 Emerg Med 2011;41(6):686-92.

5. Mohsin M, Forero R, Ieraci S, et al. A population follow-up study of patients who left an emergency department without being seen by a medical officer. Emerg Med 7 2007; 24(3):175-9.

6. Dawson H, Zinck G. CIHI survey: ED spending in Canada: a focus on the cost of patients waiting for access to an in-patient bed in Ontario. Healthc Q 2009;12(1):25-8.

7. Huang Q, Thind A, Dreyer JF, et al. The impact of delays to admission from the emergency department on inpatient outcomes. BMC Emerg Med 2010;10:16.

8. Affleck A, Parks P, Drummond A, et al. Emergency department overcrowding and access block. C7EM 2013; 15(6):359-84.

9. Alikhan LM, Howard RJ, Bowry R. From a project to transformation: how "going against the flow" led to improved access and patient flow in an academic hospital. Healthc Manage Forum 2009;22(3):20-6.

10. Allder S, Silvester K, Walley P. Managing capacity and demand across the patient journey. Clin Med 2010; 10(1):13-5.

11. Brand CA, Kennedy MP, King-Kallimanis BL, et al. Evaluation of the impact of implementation of a Medical Assessment and Planning Unit on length of stay. Aust Health Rev 2010;34(3):334-9.

12. Buckley BJ, Castillo EM, Killeen JP, et al. Impact of an express admit unit on emergency department length of stay. 7 Emerg Med 2010;39(5):669-73.

13. Cho SJ, Jeong J, Han S, et al. Decreased emergency department length of stay by application of a computerized consultation management system. Acad Emerg Med 2011; 18(4):398-402.

14. Forster AJ. An agenda for reducing emergency department crowding. Ann Emerg Med 2005;45(5):479-81.

15. Francis AJ, Ray MJ, Marshall MC. Pathology processes and emergency department length of stay: the impact of change. Med $\mathcal{F}$ Aust 2009;190(12):665-9.

16. Glasser JS, Zacher LL, Thompson JC, et al. Determination of the internal medicine service's role in emergency department length of stay at a military medical center. Mil Med 2009;174(11):1163-6.

17. Gorelick MH, Yen K, Yun HJ. The effect of in-room registration on emergency department length of stay. Ann Emerg Med 2005;45(2):128-33.

18. Hirshon JM, Kirsch TD, Mysko WK, et al. Effect of rotational patient assignment on emergency department length of stay. 7 Emerg Med 1996;14(6):763-8.

19. Holland LL, Smith LL, Blick KE. Total laboratory automation can help eliminate the laboratory as a factor in emergency department length of stay. Am 7 Clin Pathol 2006;125(5):765-70.
20. Infofinders. Leading practices in emergency department patient experience. Ottawa: Ontario Hospital Association; 2011.

21. McConnell KJ, Richards CF, Daya M, et al. Effect of increased ICU capacity on emergency department length of stay and ambulance diversion. Ann Emerg Med 2005; 45(5):471-8.

22. Olshaker JS, Rathlev NK. Emergency department overcrowding and ambulance diversion: the impact and potential solutions of extended boarding of admitted patients in the emergency department. 7 Emerg Med 2006; 30(3):351-6.

23. Schuur JD, Chu G, Sucov A. Effect of oral contrast for abdominal computed tomography on emergency department length of stay. Emerg Radiol 2010;17(4): 267-73.

24. Singer AJ, Viccellio P, Thode HCJ, et al. Introduction of a stat laboratory reduces emergency department length of stay. Acad Emerg Med 2008;15(4):324-8.

25. Viccellio P, Schneider S, Asplin BR, et al. Emergency department crowding: high-impact solutions. ACEP Task Force Report on Boarding; 2008. Available at: http://www.acep. org/WorkArea/DownloadAsset.aspx?id=50026/.

26. Wiler JL, Gentle C, Halfpenny JM, et al. Optimizing emergency department front-end operations. Ann Emerg Med 2010;55(2):142-60.e1.

27. Ontario Ministry of Health and Long-Term Care. Improving access to emergency care: addressing system issues. Ottawa: Ontario Hospital Association; 2006.

28. Hudson A, Glynn P, Trypuc J. The Wait Time Strategy review of activities, April-August 2008. Ottawa: Ontario Hospital Association; 1-10.

29. Cheng I, Lee J, Zwarenstein M, et al. Implementing waittime reductions under Ontario government benchmarks (Pay-for-Results): a cluster randomized trial of the effect of a physician-nurse supplementary triage assistance team (MDRNSTAT) on emergency department patient wait times. BMC Emerg Med 2013;13(1):17.

30. Subash F, Dunn F, McNicholl B, et al. Team triage improves emergency department efficiency. Emerg Med 7 2004;21(5):542-4.

31. Holroyd BR, Bullard MJ, Latoszek K, et al. Impact of a triage liaison physician on emergency department overcrowding and throughput: a randomized controlled trial. Acad Emerg Med 2007;14(8):702-8.

32. AHRQ Health Care Innovations Exchange: Innovations and Tools to Improve Quality and Reduce Disparities. Service delivery innovation profile-team triage reduces emergency department walkouts, improves patient care; 2013. Available at: https://innovations.ahrq.gov/profiles/team-triage-reducesemergency-department-walkouts-improves-patient-care.

33. Royal College of Emergency Medicine. Acute and emergency care: prescribing the remedy; 2014. Available at: https://www.rcplondon.ac.uk/sites/default/files/acute_and_ emergency_care_prescribing_the_remedy.pdf.

34. Iacobucci G. All emergency departments should include GP staff, say experts. BMF 2014;349, doi: 10.1136/bmj.g4654.

35. Richardson JR, Braitberg G, Yeoh MJ. Multidisciplinary assessment at triage: a new way forward. Emerg Med Australas 2004;16(1):41-6. 
36. Wykes S. New emergency department programs shorten wait times. Stanford Medicine News Center; 2013. Available at: http://med.stanford.edu/news/all-news/2013/02/newemergency-department-programs-shorten-wait-times.html.

37. Slovis C, Lemonds B. Team triage reduces emergency department walkouts, improves patient care. AHRQ Health Care Innovations Exchange 2013.

38. McHugh M, Van Dyke KJ, Yonek J, et al. Time and expenses associated with the implementation of strategies to reduce emergency department crowding. 7 Emerg Nurs 2012;38(5):420-8.

39. Kellermann AL. Calculating the cost of emergency care. Ann Emerg Med 2005;45(5):491-2.

40. Bamezai A, Melnick G, Nawathe A. The cost of an emergency department visit and its relationship to emergency department volume. Ann Emerg Med 2005;45(5):483-90.

41. Venning P, Durie A, Roland M, et al. Randomised controlled trial comparing cost effectiveness of general practitioners and nurse practitioners in primary care. BM7 2000;320(7241):1048-53.

42. Litaker D, Mion L, Planavsky L, et al. Physician-nurse practitioner teams in chronic disease management: the impact on costs, clinical effectiveness, and patients' perception of care. 7 Interprof Care 2003;17(3):223-37.

43. Ettner SL, Kotlerman J, Afifi A, et al. An alternative approach to reducing the costs of patient care? A controlled trial of the multi-disciplinary doctor-nurse practitioner (MDNP) model. Med Decis Making 2006;26(1):9-17.

44. OECD. Towards a sustainable bealth care model. Paris: OECD; 2010. Available at: http://www.oecd.org/health/ ministerial/46036456.pdf.

45. Forster AJ, Stiell I, Wells G, et al. The effect of hospital occupancy on emergency department length of stay and patient disposition. Acad Emerg Med 2003;10(2):127-33.

46. Khanna S, Boyle J, Good N, et al. Unravelling relationships: hospital occupancy levels, discharge timing and emergency department access block. Emerg Med Australas 2012; 24(5):510-7.

47. Rathlev NK, Obendorfer D, White LF, et al. Time series analysis of emergency department length of stay per 8-hour shift. West 7 Emerg Med 2012;13(2):163-8.

48. Beveridge R. CAEP issues. The Canadian Triage and Acuity Scale: a new and critical element in health care reform.
Canadian Association of Emergency Physicians. 7 Emerg Med 1998;16(3):507-11.

49. Welch S, Augustine J, Camargo CAJ, et al. Emergency department performance measures and benchmarking summit. Acad Emerg Med 2006;13(10):1074-80.

50. XE Currency. XE currency convertor-current and historical rate tables; 2014. Available at: http://www.xe.com/ currencytables/.

51. Ontario Ministry of Health and Long-Term Care. Schedule of benefits: physician services under the Health Insurance Act; 2011. Available at: http://www.health.gov.on.ca/english/ providers/program/ohip/sob/physserv/physserv_mn.html.

52. Robinson R. Economic evaluation and health care. What does it mean? BMF 1993;307(6905):670-3.

53. Robinson R. Cost-effectiveness analysis. BMF 1993; 307(6907):793-5.

54. Robinson R. Cost-utility analysis. BM7 1993;307(6908):859-62.

55. Debehnke D, Decker MC. The effects of a physician-nurse patient care team on patient satisfaction in an academic ED. Am 7 Emerg Med 2002;20(4):267-70.

56. Drummond MF, Sculpher MJ, Torrance GW, et al. Methods for the economic evaluation of health care programmes. Oxford: Oxford University Press; 2005.

57. Statistics Canada. Average hourly wages of employees by selected characteristics and occupation, unadjusted data by province (monthly)(Ontario). Available at: http://statcan. gc.ca/tables-tableaux/sum-som/101/cst01/labr69g-eng.htm.

58. Van den Berg B, Gafni A, Portrait F. Attributing a monetary value to patients' time: a contingent valuation approach. CHE Research Paper 90 [dissertation]. York, UK: The University of York; 2013. Available at: http://www.york.ac. uk/media/che/documents/papers/researchpapers/CHERP90_ monetary_value_patient_time_contingent_valuation.pdf.

59. OECD. OECD Health Data 2009. Comparing health statistics across OECD countries; 2009. Available at: http:// www.oecd.org/health/oecdhealthdata2009comparinghealthstatisticsacrossoecdcountries.htm.

60. Atun R, de Jongh T, Secci F, et al. Integration of targeted health interventions into health systems: a conceptual framework for analysis. Health Policy Plan 2010;25(2):104-11.

61. World Health Organization. Systems thinking for health systems strengthening (Nonserial Publications). Geneva: World Health Organization; 2010. 